University of Wollongong

Research Online

Faculty of Informatics - Papers (Archive)

Faculty of Engineering and Information

Sciences

$1-1-2009$

\title{
Effects of novel hybrid and traditional rootstocks on vigour and yield components of Shiraz grapevines
}

T H. Jones

CSIRO

B R. Cullis

NSW Department of Primary Industries, bcullis@uow.edu.au

P R. Clingeleffer

CSIRO

E H. Ruhl

CSIRO

Follow this and additional works at: https://ro.uow.edu.au/infopapers

Part of the Physical Sciences and Mathematics Commons

\section{Recommended Citation}

Jones, T H.; Cullis, B R.; Clingeleffer, P R.; and Ruhl, E H.: Effects of novel hybrid and traditional rootstocks on vigour and yield components of Shiraz grapevines 2009, 284-292.

https://ro.uow.edu.au/infopapers/2105

Research Online is the open access institutional repository for the University of Wollongong. For further information contact the UOW Library: research-pubs@uow.edu.au 


\title{
Effects of novel hybrid and traditional rootstocks on vigour and yield components of Shiraz grapevines
}

\begin{abstract}
Background and Aims: The influence of grapevine rootstocks on vine vigour and crop yield is recognized as an integral part of viticultural management. However, the genetic potential of Vitis species rootstock hybrids for vigour and yield control is not fully exploited in Australian viticulture. The effect of 55 novel inter- and intra-species hybrids and five traditional hybrid rootstock cultivars on winter pruning weight, berry size and fruit yield of grafted Shiraz vines is presented. The genetic predictions that resulted from this analysis were used to illustrate how rootstocks that best perform for a combination of traits may be selected.

Methods and Results: The use of linear mixed models and residual maximum likelihood procedures took into account repeated measures and spatial variation within a large field trial (720 vines). Over 6 years of assessment, variation of up to $93.9 \%$ in winter pruning weight, $81.9 \%$ in fruit yield and $21.0 \%$ in berry weight between rootstocks was estimated.

Conclusions: The effect of rootstock genotype accounted for marked differences in conferred pruning weight, berry weight and fruit yield from trial averages. Comparison of statistical analysis techniques illustrated that the choice of such techniques may influence the outcome of genetic selection from field trial data.

Significance of the Study: Such quantification of the variation between vines in vigour, fruit yield and berry size due to rootstock genotype provides a framework for selection of well-performing genotypes for inclusion in advanced generations of the CSIRO vine rootstock breeding program.

\section{Keywords}

traditional, novel, effects, vigour, yield, components, shiraz, rootstocks, hybrid, grapevines

Disciplines

Physical Sciences and Mathematics

\section{Publication Details}

Jones, T. H., Cullis, B. R., Clingeleffer, P. R. \& Ruhl, E. H. (2009). Effects of novel hybrid and traditional rootstocks on vigour and yield components of Shiraz grapevines. Australian Journal of Grape and Wine Research, 15 (3), 284-292.
\end{abstract}


1 Effects of novel hybrid and traditional rootstocks on vigour and yield

2 components of Shiraz grapevines.

3

$4 \quad$ T.H. Jones ${ }^{1,4}$, B.R. Cullis ${ }^{2}$, P.R. Clingeleffer ${ }^{1}$, and E.H. Rühl ${ }^{1,3}$

5

$6 \quad{ }^{1}$ CSIRO Division of Plant Industry, PMB, Merbein, Vic., 3505

$7 \quad{ }^{2}$ NSW Department of Primary Industries Wagga Wagga Agricultural Institute

$8 \quad{ }^{3}$ Current address: Geisenheim Research Centre, Section for Grapevine Breeding and

9 Grafting, 65366 Geisenheim, Germany

$10 \quad{ }^{4}$ Corresponding Author: Tim H. Jones. Current address: Yalumba Nursery, PO Box

11 10, Angaston, SA, 5355. Facsimile: + 618 85687710. Email: tjones@yalumba.com. 12 


\section{Abstract}

\section{Background and Aims}

3 The influence of grapevine rootstocks on vine vigour and crop yield is recognised as

4 an integral part of viticultural management. However, the genetic potential of Vitis

5 species rootstock hybrids for vigour and yield control is not fully exploited in

6 Australian viticulture. The effect of 55 novel inter- and intra-species hybrids and five

7 traditional hybrid rootstock cultivars on winter pruning weight, berry size and fruit

8 yield of grafted Shiraz vines is presented. The genetic predictions that resulted from

9 this analysis were used to illustrate how rootstocks that best perform for a

10 combination of traits may be selected.

\section{Methods and Results}

12 The use of linear mixed models and residual maximum likelihood procedures took

13 into account repeated measures and spatial variation within a large field trial (720

14 vines). Over six years of assessment, variation of up to $93.9 \%$ in winter pruning

15 weight, $81.9 \%$ in fruit yield and $21.0 \%$ in berry weight between rootstocks was

16 estimated.

17 Conclusions

18 The effect of rootstock genotype accounted for marked differences in conferred

19 pruning weight, berry weight and fruit yield from trial averages. Comparison of

20 statistical analysis techniques illustrated that the choice of such techniques may

21 influence the outcome of genetic selection from field trial data.

22 Significance of Study

23 Such quantification of the variation between vines in vigour, fruit yield and berry size

24 due to rootstock genotype provides a framework for selection of well performing

25 genotypes for inclusion in advanced generations of the CSIRO vine rootstock

26 breeding program.

27

28 Keywords: Grapevine breeding, BLUP, rootstock, yield components, vigour. 
3 The use of non Vitis vinifera rootstocks in wine grape production provides a platform

4 for manipulation of a broad range of vine characteristics which can consequently

5 improve vineyard efficiency (Whiting 2004). Since the initial adoption of non $V$.

6 vinifera rootstocks, primarily to provide grafted vines with resistance to the grape

7 phylloxera (Daktulosphaira vitifoliae) (de Castella 1921), rootstocks have been

8 selected to confer a wide range of other traits for grapevine improvement. These

9 include resistance to nematodes (Stirling and Cirami 1984; McKenry and Anwar 2006) as well as other soil-borne pathogens (Ferreira and Marais 1987; Walker et al. 1994; Sule and Burr 1998), adaptability to soil pH (Conradie 1983; Bavaresco et al. 2003), salinity tolerance (Sauer 1968; Downton 1977; Walker et al. 2002; Walker et al. 2004), drought tolerance (Carbonneau 1985; McCarthy et al. 1997), adaptability to water logging (Whiting and Orr 1990; Striegler et al. 1993), ability to mediate nutrient uptake and juice and wine composition (Bénard et al. 1963; Hale and Brien 1978; Ruhl et al. 1988; Walker et al. 1998; Walker et al. 2000; Mpelasoka et al. 2003), and the ability to control vine vigour and yield components (Rives 1971; Ruhl et al. 1988; May 1994; Reynolds and Wardle 2001).

With grapevine vigour and yield closely related to fruit composition and wine quality (Kliewer and Weaver 1971; Bravdo 1985; Clingeleffer et al. 2000; Kliewer and Dokoozlian 2005), considerable resources may be required to manage these traits in commercial vineyards that aim to maximize profitability by optimizing yield and quality (Clingeleffer and Sommer 1995; Dry et al. 1999). Rootstocks may be utilized to influence vigour and fruit yield, with the potential to reduce reliance on standard traditional viticultural techniques such as vine training, pruning and fruit thinning (Pouget 1987; Delas 1992; Clingeleffer et al. 1999; Clingeleffer et al. 2000). Significant variation in conferred vigour and yield have been identified between traditional rootstock varieties (Harmon 1949; Lipe and Perry 1988; Pouget and Delas 1989; Prior et al. 1993; Main et al. 2002; Zerihun and Treeby 2002), most of which are non $V$. vinifera species hybrids or pure non V. vinifera species (Pongrácz 1983; May 1994). Specifically, such rootstocks have been shown to directly influence vigour and yield controlling physiological processes such as nitrogen uptake (Williams and Smith 1991; Keller et al. 2001b; Keller et al. 2001a; Zerihun and Treeby 2002) and photosynthesis (Düring 1994; Koblet et al. 1997; Soar et al. 2006). 
1 With the influence of rootstock variety on vigour and yield potentially under strong

2 genetic control, the potential for breeding to improve rootstock effects on wine grapes

3 is clearly evident (Alleweldt and Possingham 1988; Read and Gu 2003; Cousins

4 2005). However, despite other reports in the literature, a level of ambiguity still

5 remains around the genetic potential that resides within the broad range of rootstock

6 germplasm available, perhaps due in part to the interaction of management techniques

7 and other environmental variables on the performance of the traditional rootstock

8 varieties (May 1994; Read and Gu 2003). Indeed, relatively few grapevine rootstock

9 varieties are used extensively by the grape industry, with preference given to varieties

10 that have historically proven to perform well (May 1994; de Andres et al. 2007). In

11 comparison to the European industry, grafted vines are still a minority in Australian

12 vineyards with $18.9 \%$ of the total area of Australian vineyards planted with grafted

13 vines in 2006 (Dry 2007). Hence, in recent years, rootstock breeding in Australia has

14 moved towards the screening of non-traditional multi-species hybrids for suitability to

15 local conditions (Clingeleffer 1996; Wheal et al. 2002).

16 The efficacy of such breeding programs depends foremost on the accurate genetic

17 assessment (e.g. Cotterill and Dean 1990; Cullis et al. 2000) of the effect of rootstock

18 varieties on scions (Rives 1971) which will lead to a more accurate prediction of the

19 outcome of selective breeding. In this paper, we used linear mixed models and

20 residual maximum likelihood procedures (Gilmour et al. 1995) to take into account

21 various aspects of the environmental, temporal, and genetic variation residing within

22 the trial to more accurately partition the variance due to each variable (Gilmour et al.

23 1997). This allowed the calculation of the best linear unbiased predictions (BLUPs,

24 Robinson 1991) of the effects of 55 non-traditional multi-species hybrid rootstocks

25 and 5 traditional rootstock varieties on mature grafted Shiraz grapevines. We

26 investigated rootstocks effects on vine vigour (measured as winter pruning weight

27 following Ravaz (1911) and Rives (1971)), berry weight and fruit yield over six years

28 of observations. In addition, the genotypes identified by this contemporary statistical

29 analysis that best satisfied a predefined multi-trait selection regime were compared to

30 those identified with the use of arithmetic trial means alone. This comparison clearly

31 illustrated how the choice of statistical analysis technique may influence the outcome

32 of genetic selection from field trial data. 
1 Materials and Methods

2

$3 \quad$ Trial site and design

4 The trial was established in 1989 at Koorlong (34 $15^{\prime} 32^{\prime \prime} \mathrm{S}, 142^{\circ} 7^{\prime}$ 59" E) in the

5 warm climate inland irrigation region of Sunraysia (Victoria, Australia). The trial is

6 situated on sandy calcareous earths (Northcote 1988), on a slight north-south slope

7 with east-west running rows $3 \mathrm{~m}$ apart, with $1.8 \mathrm{~m}$ between vines along rows.

8 The trial, consisting of 6 replicates (2 vine plots) of each rootstock genotype, was

9 planted in 1989, with vine propagation and grafting carried out in 1988. Vines were

10 bench grafted and planted in the same season. It was assessed over 6 years from 1993

11 to 1998 . The trial was designed with 5 of the 6 replicates planted as adjacent

12 complete blocks, with the sixth replicate split into two incomplete blocks situated at

13 either end of the five adjacent complete blocks. Once established, the vines were spur

14 pruned (bud load approximately 80 buds per vine) with cordons developed on a two

15 wire vertical trellis. Standard commercial management practices for the region were

16 applied to the field trial, with approximately $0.7 \mathrm{~m}$ of water applied per year by

17 overhead sprinklers.

19 Data collection

20 Winter pruning weights were recorded, measuring total fresh pruning wood weight for

21 each vine. Total fruit yield (whole bunches) was recorded for each vine, with 5

22 berries (two from the top, two from the middle and one from the base) from 20

23 bunches weighed to calculate average berry weight for each vine. When sampling

24 berries, bunches were sampled in equal numbers from both sides of the vine, sampling

25 bunches evenly along cordons where possible, immediately prior to harvesting all

26 bunches.

28 Genetic background of material

29 All rootstocks were grafted to Shiraz clone PT23. The five traditional rootstocks

30 consisted of two V. candicans x V. rupestris natural hybrids Dog Ridge and Ramsey,

31 both previously regarded as $V$. champinii (see Pongrácz 1983), two V. berlandieri x $V$.

32 rupestris hybrids 1103 Paulsen and 140 Ruggeri, and the multispecies complex hybrid

33 Freedom with a pedigree involving $V$. vinifera, V. labrusca, $V$. riparia, and $V$.

34 rupestris. The 55 non-traditional rootstocks consisted of intra- and inter-species 
1 hybrids (Table 1), including some selections that did not have a fully resolvable pedigree (denoted u.p.). Three of these hybrids (2 - Merbein 5489, 3 - Merbein 5512 and 12 - Merbein 6262) are CSIRO selections that have recently been released to the Australian viticultural industry.

Statistical Analysis

8 Trial data was analysed using linear mixed models and the residual maximum likelihood procedure with ASREML-R (Butler et al. 2007). Rootstock genotype (i.e., 10 a factor with 60 levels) defined the "treatment" structure while block, field row, field 11 column and field plot (with 6, 12, 60, 360 levels respectively) were included in all 12 models as random terms to account for either the design randomisation processes or 13 extraneous variation arising from spatial heterogeneity in the field.

14 As a small number of vines were replaced after early stage mortality (propagated in 15 the same way as the original vines), a covariate based on the year of re-planting was created and included in all models as a fixed term. Where necessary additional covariance models were included at the residual level, typically based on the separable first order autoregressive model described in Cullis and Gleeson (1991). To account for spatial variation not adequately dealt with by the randomized trial design, spatial covariance models were applied in the field row and field column direction where appropriate (Cullis and Gleeson, 1991). Similarly, to account for temporal correlation across years (e.g. Verbyla and Cullis 1992; Jaffrezic and Pletcher 2000), covariance models were included for each random term which contributed in a major way to the total variation. Covariance models used included the uniform and antedependence models as appropriate (Wolfinger 1996; Jaffrezic et al. 2003). An antedependence covariance model was also used for the residuals. To best describe the effect of rootstock genotype on grafted vine performance, Best Linear Unbiased Predictors (BLUPs) (Robinson 1991) of rootstock genotype values and standard errors were calculated. The accuracy of these was computed using a generalised measure of broad-sense heritability (Cullis et al. 2006) which is defined as the square of the correlation between predicted and true genetic effects (Falconer and Mackay 1996; Oakey et al. 2006). Total genetic correlations (combining additive and non-additive effects) over years were also obtained from the fitted 
1 Arithmetic means across all years were also calculated for each trait to allow comparison with rootstock genotype predictions based on BLUP estimates. An arbitrary selection regime that identified potential commercially favourable rootstocks, in terms of the traits examined in this study, was then applied to illustrate how the identification of optimal genotypes may differ depending on the statistical technique used for genotype evaluation. This selection regime identified rootstocks that conferred low to medium vine vigour, medium to high yield, small berry size whilst maintaining vine balance (Smart 1991).

(1)

\section{Results}

\section{(2)}

The three traits examined in this study where strongly influenced by rootstock genotype, illustrated by comparisons of the genotype BLUP values that predict the effect of each rootstock genotype on grafted vine performance. A 93.9\% decrease in pruning weight between vines with the most and least vigourous rootstock genotypes (Figure 1a), an $81.9 \%$ decrease in fruit yield between vines with the most and least productive rootstock genotypes (Figure $1 \mathrm{~b}$ ) and a $21.0 \%$ decrease in berry weight between vines with the largest and smallest berry producing rootstock genotypes (Figure 1c) was observed. REML estimates of total genetic correlations between years ranged between $r_{g}=0.85$ and $r_{g}=0.99$ for pruning weight and $r_{g}=0.69$ and $r_{g}$ $=0.93$ for fruit yield. Such high genetic correlations indicate relatively high consistency from year to year. However in both traits (in particular fruit yield, Table 2), a decrease in genetic correlation with increasing time between observations was evident, hence, the ante-dependence covariance structure over years described earlier was fitted in the model. Genetic correlations between years in berry weight ranged 7 between $r_{g}=0.53$ and $r_{g}=0.82$, however there was no such pattern of decline in 8 correlation over time. Single year generalised broad-sense heritabilities for pruning 9 weight and fruit yield ranged from $h_{g}^{2}=0.87-0.90($ mean $=0.89)$ and $h_{g}^{2}=0.81-0.91$ (mean $=0.89$ ) over the six years of assessment (Table 3$)$, indicating a high level of 1 accuracy in the prediction of rootstock genotype values. The generalized heritability of berry weight was more variable over years $\left(h_{g}^{2}=0.50-0.76\right.$, mean $\left.=0.69\right)$, however still suggesting a considerable correlation between predicted and real genetic 4 values. 
1 All traditional rootstock varieties produced more vigourous, productive vines with

2 larger berry size than the trial means. The two CSIRO selections Merbein 5512 (3)

3 and Merbein 6262 (12) displayed considerably lower pruning weight, yield and berry

4 size than the trial mean (Figure 1). Merbein 5489 (2) displayed a pruning weight and

5 yield not significantly different from the trial mean, while displaying smaller berry

6 size (Figure 1).

7 The ranking of rootstock genotype performance based on BLUPs showed marked

8 differences to that based on trial means (Figure 2). Of the 21 low vigour genotypes

9 that would be selected under an arbitrary low vigour pruning weight range of 1.0 to

$10 \quad 2.0 \mathrm{~kg}$ based on BLUP values, sixteen genotypes were selected in common with those

11 identified for the same selection range using trial means, with two additional

12 genotypes identified using trial means, that fell outside the specified range of BLUP

13 genotype values. Similarly, differences were identified when applying a medium to

14 high yield selection range of between 10.0 and $11.0 \mathrm{~kg}$, and a low berry weight

15 selection range of 1.2 to $1.3 \mathrm{~g}$ (Figure 2). When genotypes were ranked by the 16 commonly used Ravaz Index (ratio of vine yield (kg) to pruning weight (kg), Ravaz

17 (1911)), differences between estimates based on the two approaches were magnified,

18 especially in genotypes that produced vines which showed a larger yield to vigour

19 ratio (Figure $2 \mathrm{~d}$ ).

20 When an arbitrary selection range for the Ravaz Index of between 8.0 and 10.0 was

21 applied, that would identify vines that exhibit relative high yield per mass of prunings,

22 but remain "in balance" (Bravdo et al. 1984; Bravdo 1985; Smart 1991), none of the

23 four genotypes selected using BLUP values of yield and pruning weight were

24 identified using the trial means approach (Figure 2d). Instead, three different

25 genotypes were identified when trial means for yield and pruning weight of genotypes

26 were used.

27 When the rootstock yield BLUPs were plotted against those for pruning weight, the

28 positive relationship between yield and vine vigour identified by past studies (e.g.

29 Walker et al. 2002) was evident (Figure 3). This plot also provides the opportunity to

30 graphically illustrate how genotypes that satisfy both the yield and pruning weight

31 selection ranges discussed above can be rapidly identified (Figure 3). On this basis,

32 three optimal genotypes $(19,43,45)$ are identified. However, with none of these

33 genotypes satisfying the initial berry weight selection range and Ravaz Index selection

34 range (displaying vigour $(\mathrm{kg}) /$ pruning weight $(\mathrm{kg})=6.3,7.2$ and 5.3 respectively) 
1 applied, it was necessary to loosen constraints to allow selection of an appropriate number $(10 \%)$ of best performing genotypes.

3 When applying a pruning weight selection range of between 1.0 and $2.0 \mathrm{~kg}$, a yield selection range of between 8.0 and $11.0 \mathrm{~kg}$, a berry weight criterion of less than $1.4 \mathrm{~g}$ and a Ravaz Index range of between 5.0 and 10.0 (indicative of "vine balance", Smart 1991), $10 \%$ of the genotypes examined are identified as optimal genotypes under the management conditions of this trial with Shiraz as the scion variety (Table 4). It was interesting to note that all traditional rootstock varieties showed low Ravaz Indices $(<$ 5.0) under the trial management conditions (Figure 3).

\section{Discussion}

13 The performance of Shiraz grapevines in the replicated field trial environment was 14 heavily influenced by rootstock genotype, reflecting the genetic diversity conferred by the broad range of Vitis species (de Andres et al. 2007) that comprise the genetic backgrounds of the rootstocks examined in this experiment. Marked differences between rootstock genotypes in conferred vigour, yield and berry weight, over six years of observations, were estimated with the use of Best Linear Unbiased Predictions (BLUPs, e.g. Robinson 1991, Welham et al. 2004). These predictions clearly illustrate the considerable potential of rootstocks to mediate vine performance. In addition, such variability between genotypes clearly suggests that significant gains may be realised by selective breeding to combine and amplify beneficial traits (Cotterill and Dean 1990; Falconer and Mackay 1996).

In woody perennial species that generally require a number of years between germination and reproductive (and fully productive) maturity, it is imperative that such predictions of breeding values are as accurate as possible to optimise efficiency of selection and advanced generation breeding (Cotterill and Dean 1990; Falconer and Mackay 1996). When spatial and temporal variables were appropriately modelled in this analysis, substantial differences in the predicted performance of genotypes to that estimated by arithmetic trial means were identified.

31 In the case of vine vigour in the current study, measured as total winter pruning weight, genetic correlations between the six years of observations were high $\left(r_{g} \geq\right.$ 0.85 ) indicating that observations carried out over a shorter number of years may 34 provide adequate information in this trial, depending on the desired level of accuracy. 
1 Consistently high values of generalised broad-sense heritability $\left(h_{g}^{2}=0.87-0.90\right)$ for rootstock genotype effect on vine pruning weight over the six years of observations suggest a high level of accuracy in the BLUP predictions. Dog Ridge ( $V$. candicans $\mathrm{x}$ $V$. rupestris) produced the most vigourous vines within the trial over the six years of observations. Conversely, the inter-species hybrid genotype 32 (a complex hybrid with a pedigree dominated by $V$. Vinifera and $V$. rotundifolia that was not-completely resolved due to an open-pollination event in the selection's background) conferred the lowest winter pruning weights of the 60 genotypes analysed, producing $93.9 \%$ less pruning weight than Dog Ridge. The five traditional rootstock varieties in this trial conferred moderately high to very high vigour, with each variety closely matching that described in the literature (summarised by Whiting 2004). It is interesting to note that studies of ungrafted table grape hybrids have identified a much lower heritability of vine vigour (broad-sense heritability not significantly different from zero, Firoozabady and Olmo 1987, narrow-sense $h^{2}=0.22$, Wei et al. 2003a). Genetic correlations for total fruit yield among years declined with increasing time between observations. However, beyond the first year of observations (vine age of 5 years), predicted rootstock genotype values from each year correlated well with each other $\left(r_{g}\right.$ $\geq 0.80$ ). Following an expected close association between fruit yield and vine vigour (Walker et al. 2002), genotype 32 also conferred the lowest fruit yield, producing $81.9 \%$ less fruit than the highest yielding genotype 23 (V. candicans $\mathrm{x} V$. rupestris $\mathrm{x}$ $V$. vinifera hybrid, Table 1). As was the case for conferred vine vigour, a high level of accuracy in the predicted effects of rootstock genotypes on conferred fruit yield was indicated by consistently high generalised broad-sense heritabilities $\left(h_{g}^{2}=0.81-0.91\right)$ over the six years of observations. Assuming our generalized broad-sense heritability estimates are describing a significant proportion of additive genetic variation, this again contrasted with that observed in ungrafted table grape hybrids, with Wei et al. (2003a) reporting a narrow sense heritability (Falconer and Mackay 1996) estimate of $\left(h^{2}=0.18\right)$ for fruit yield among the diverse range of table grape bi-parental progeny studied. This raises the possibility that genetic variation in conferred winter pruning weight and fruit yield conferred by rootstocks of such a diverse species background may be somewhat greater than that residing among pure $V$. vinifera varieties. However, the population specific estimates of generalized broad-sense heritability in this study of a relatively small population do not take into account genetic by environment interactions, and do not partition additive and non-additive components 
1 of genetic variation (e.g. Oakey et al. 2006). Rootstock field trial designs that

include appropriate family pedigree size and structure to allow accurate narrow-sense heritability estimates of rootstock genotype effects are necessary to quantify this with more accuracy (Falconer and Mackay 1996).

Genetic correlations in berry weight across years were as low as $r_{g}=0.53$ (between 1993 and 1994) and did not display any clear trend with time between observations, indicating that selection for rootstock influence on berry weight may not be able to be made reliably from any one single year of results. This also indicated that the inclusion of the standard exponential decay covariance structure for repeated measures in the model was not appropriate for this trait. The lower heritability values for conferred berry weight in comparison to fruit yield and pruning weight could be caused by weaker genetic control in this situation, reduced genetic variability in this trait within the genetic material studied (as seen in the relatively narrow range of berry weight BLUP values), a sampling methodology that is prone to more error than the total yield and pruning weight measures, or a combination of these factors. Nonetheless, with an average generalised heritability of $h_{g}^{2}=0.69$ and significant variation between genotypes in BLUP values under trial conditions, berry size is clearly influenced by rootstock genotype. It is interesting to note that the largest berries occurred on vines grafted to the $V$. vinifera $\mathrm{x} V$. longii hybrid genotype 37 , with $72 \%$ of these particular hybrids conferring larger berry sizes than the trial mean. In addition, the five traditional rootstock varieties produced larger berries than the trial mean. Narrow-sense heritability estimates for berry size among $V$. vinifera table grape hybrids was estimated at $h^{2}=0.63$ by Wei et al. (2002), indicating that berry weight in the ungrafted grapevines is under strong additive genetic control and that significant genetic improvement in berry size may be achieved with selective breeding (Wei et al. 2003b). Under the management conditions applied to the field trial, all traditional rootstock varieties produced vines that had a yield to pruning weight ratio of less than 5.0, below the optimal threshold suggested by authors such as Bravdo et al. (1984) Bravdo (1985) and Smart (1991) for optimal vine balance in terms of fruit quality (e.g. Kliewer and Dokoozlian 2005). With a reduction in yield response to pruning weight evident in high vigour rootstocks in this study, it is apparent that the nontraditional hybrid genotypes that conferred less vigour than the traditional varieties in 
1 environment and management regime. By considering the BLUP genotype values for

2 all three traits, it was possible to illustrate how ten percent of the genotypes studied

3 that best satisfied predefined yield, vigour and berry weight prerequisites could be

4 selected, in the absence of genotype by environment information. While this provides

5 an example of multi-trait selection (Falconer and Mackay 1996) in its most simplistic

6 form, it illustrates the significant potential that exists for development of improved

7 grapevine rootstocks that are specific to industry requirements. Recently, highly

8 replicated grafted rootstock genetic trials that comprise a broad range of germplasm

9 and include the pedigree structure required to allow estimation of additive genetic

10 effects (Falconer and Mackay 1996), have been implemented. These trials will

11 provide information on the genetic control of a range of crucial traits with high

12 resolution and facilitate the development of a functional multi-trait selection index

13 that will significantly improve the efficiency of grapevine rootstock breeding in 14 Australia.

15

16

17

18

19

20

21

22

David Emanuelli for data collection. Steve Sykes, Craig Hardner, Jo Stringer, Brady

23 


\section{References}

Alleweldt G., Possingham J. V. (1988) Progress in Grapevine Breeding. Theoretical and Applied Genetics 75, 669-673.

Bavaresco L., Giachino E., Pezzutto S. (2003) Grapevine rootstock effects on limeinduced chlorosis, nutrient uptake, and source-sink relationships. Journal of Plant Nutrition 26, 1451-1465.

Bénard P., Jouret C., Flanzy M. (1963) Influence des porte-greffes sur la composition minérale des vins. Annales de technologie agricole 12, 277-285.

Bravdo B. (1985) Effect of crop level and crop load on growth, yield, must and wine composition, and quality of Cabernet Sauvignon. American Journal of Enology and Viticulture 36, 125.

Bravdo B., Hepner Y., Loinger C., Cohen S., Tabacman H. (1984) Effect of crop level on growth, yield and wine quality of a high yielding Carignane vineyard. American Journal of Enology and Viticulture 35, 247-252.

Butler D., Cullis B. R., Gilmour A. R., Gogel B. J. (2007) 'ASReml-R reference Manual Release 2.0.' (Queensland Department of Primary Industries and Fisheries. Available online at http://www.vsni.co.uk/resources/doc/asreml-R.pdf.: Brisbane)

Carbonneau A. (1985) The early selection of grapevine rootstocks for resistance to drought conditions. American Journal of Enology and Viticulture 36, 195-198.

Clingeleffer P. R. (1996) Rootstocks: A means to control scion pH, ion composition and spectral parameters and meet juice and wine quality specifications. In 'Quality Management in Viticulture: ASVO Viticulture Seminar'. Mildura Arts Centre, 2 August. (ASVO)

Clingeleffer P. R., Krstic M. P., Sommer K. J. (2000) Production efficiency and relationships among crop load, fruti composition, and wine quality. In 'Proceedings of the American Society for Enology and Viticulture 50 ${ }^{\text {th }}$ Anniversary Meeting, Seattle, June 19-23' pp. 318-322

Clingeleffer P. R., Sommer K. J. (1995) Vine development and vigour control. In 'Canopy management: proceedings of a seminar organized by the Australian Society of Viticulture and Oenology, Mlidura, 1994'. (Ed. P Hayes). (Winetitles, Adelaide)

Clingeleffer P. R., Sommer K. J., Walker R. R. (1999) Hollistic system approach for sustainable vineyard management for grape and wine quality. In 'Proceedings of the Tenth Australian Wine Industry Technical Conference'. Sydney. (Eds RJ Blair, AN Sas, PF Hayes and PB Høj) pp. 188-196. (The Australian Wine Research Institute Urrbrae)

Conradie W. J. (1983) Liming and choice of rootstocks as cultural techniques for vines in acid soils. South African Journal of Enology and Viticulture 4, 39-44. 
1 Cotterill P. P., Dean C. A. (1990) Successful Tree Breeding with Index Selection

2 (CSIRO: Melbourne)

Cousins P. (2005) Evolution, genetics and breeding: Viticultural applications of the origins of our rootstocks. In 'Grapevine Rootstocks: Current Use, Research and Application Proceedings of the 2005 rootstock symposium'. Osage Beach, Missouri. (Eds P Cousins and K Striegler). (Mid-America Viticulture and Enology Center Southwest Missouri State University Mountatin Grove Campus)

Cullis B. R., Smith A. B., Hunt C., Gilmour A. (2000) An examination of the efficiency of Australian crop variety evaluation programmes. Journal of Agricultural Science 135, 213-222.

Cullis B. R., Gleeson A.C. (1991) Spatial-analysis of field experiments - an extension in 2 dimensions. Biometrics 47, 1449-1460.

Cullis B. R., Smith A. B., Coombes N. E. (2006) On the design of early generation variety trials with correlated data. Journal of Agricultural, Biological and Environmental Statistics 11, 381-393.

de Andres M. T., Cabezas J. A., Cervera M. T., Borrego J., Martinez-Zapater J. M., Jouve N. (2007) Molecular characterization of grapevine rootstocks maintained in germplasm collections. American Journal of Enology and Viticulture 58, 75-86.

de Castella F. R. (1921) Resistant Stocks. The Journal of the Department of Agriculture of Victoria 19, 490-499.

Delas J. J. (1992) Criteria used for rootstock selection in France. In 'Rootstock Seminar: A Worldwide Perspective'. Reno, Nevada. (Eds JA Wolpert, MA Walker and E Weber) pp. 1-14. (American Society for Enology and Viticulture)

Downton W. J. S. (1977) Chloride accumulation in different species of grapevine. Scientia Horticulturae 7, 249-253.

Dry P. R., Loveys B. R., Illand P. G., Botting D. G., McCarthy M. G. (1999) Vine manipulation to meet fruit specifications. In 'Proceedings of the Tenth Australian Wine Industry Technical Conference'. Sydney. (Eds RJ Blair, AN Sas, PF Hayes and H P.B.) pp. 208-214. (The Australian Wine Research Institute)

Dry N. (2007) Grapevine Rootstocks Selection and Management for South Australian Vineyards. (Lythrum: Press Adelaide)

Düring H. (1994) Photosynthesis of ungrafted and grafted vines: effects of rootstock genotype and plant age. American Journal of Enology and Viticulture 45, 297-299.

Falconer D. S., Mackay T. F. C. (1996) Introduction to Quantitative Genetics. (Addison Wesley Longman Ltd.: Dinburgh Gate, Harlow, Essex) 
Ferreira J. H. S., Marais P. G. (1987) Effect of rootstock cultivar, pruning method and crop load on Botrytis cinerea rot of Vitis vinifera cv. Chenin Blanc grapes. South African Journal of Enology and Viticulture 8, 41-44.

Firoozabady E., Olmo H. P. (1987) Heritability and correlation studies of certain quantitative traits in table grapes, Vitis spp. Vitis 26, 132-146.

Gilmour A., Cullis B. R., Verbyla A. P. (1997) Accounting for natural and extraneous variation in the analysis of field experiments. Journal of Agricultural, Biological, and Environmental Statistics 2, 269-293.

Gilmour A. R., Thompson R., Cullis B. R. (1995) Average information REML: An efficient algorithm for variance parameter estimation in linear mixed models. Biometrics 51, 1440-1450.

Hale C. R., Brien C. J. (1978) Influence of Salt Creek rootstocks on composition and quality of Shiraz grapes and wine. Vitis 17, 139-146.

Harmon F. N. (1949) Comparitive value of thirteen rootstocks for ten vinifera grape varieties in the Napa Valley in California. Proceedings of the American Society of Horticultural Science 54, 157-162.

Jaffrezic F., Pletcher S. D. (2000) Statistical models for estimating the genetic basis of repeated measures and other function-valued traits. Genetics 156, 913-922.

Jaffrezic F., Thompson R., Hill W. G. (2003) Structured antedependence models for genetic analysis of repeated measures on multiple quantitative traits. Genetical Research 82, 55-65.

Keller M., Kummer M., Vasconcelos M. C. (2001a) Reproductive growth of grapevines in response to nitrogen supply and rootstock. Australian Journal of Grape and Wine Research 7, 12-18.

Keller M., Kummer M., Vasconcelos M. C. (2001b) Soil nitrogen utilisation for growth and gas exchange by grapevines in response to nitrogen supply and rootstock. Australian Journal of Grape and Wine Research 7, 2-11.

Kliewer W. M., Dokoozlian N. K. (2005) Leaf area/crop weight ratios of grapevines: Influence on fruit composition and wine quality. American Journal of Enology and Viticulture 56, 170-181.

Kliewer W. M., Weaver R. J. (1971) Effect of crop level and leaf area on growth, composition, and coloration of 'Tokay' grapes. American Journal of Enology and Viticulture 22, 172-177.

Koblet J. R., Keller M., Candolfi-Vasconcelos M. C. (1997) Effects of training system, canopy management practices, crop load and rootstock on grapevine photosynthesis. Acta Horticulturae 427, 133-140. 
1 Lipe W. N., Perry R. L. (1988) Effects of Rootstocks on Wine Grape Scion Vigor,

2 Yield, and Juice Quality. Hortscience 23, 317-321.

Main G., Morris J., Striegler K. (2002) Rootstock effects on Chardonel productivity, fruit, and wine composition. American Journal of Enology and Viticulture 53, 37-40.

May P. (1994) Using Grapevine Rootstocks: The Australian Perspective. (Winetitles: Adelaide)

McCarthy M. G., Cirami R. M., Furkaliev D. G. (1997) Rootstock response of Shiraz (Vitis vinifera) grapevines to dry and drip-irrigated conditions. Australian Journal of Grape and Wine Research 3, 95-98.

McKenry M. V., Anwar S. A. (2006) Nematode and grape rootstock interactions including an improved understanding of tolerance. Journal of Nematology 38, 312318.

Mpelasoka B. S., Schachtman D. R., Treeby M. T., Thomas M. R. (2003) A review of potassium nutrition in grapevines with special emphasis on berry accumulation. Australian Journal of Grape and Wine Research 9, 154-168.

Northcote K. H. (1988) Soils and Australian Viticulture. In 'Viticulture Volume 1 Resources'. (Eds BG Coombe and PR Dry) pp. 81. (Australian Industrial Publishers: Adelaide)

Oakey H., Verbyla A., Pitchford W., Cullis B., Kuchel H. (2006) Joint modeling of additive and non-additive genetic line effects in single field trials. Theoretical and Applied Genetics 113, 809-819.

Pongrácz D. P. (1983) Rootstocks for Grape-vines. (David Philip: Cape Town)

Pouget R. (1987) Usefulness of rootstocks for controlling vine vigour and improving wine quality. Acta Horticulturae 206, 109-113.

Pouget R., Delas J. J. (1989) Le choix des porte-greffe de la vigne pour une production de qualité. Connaissance de la Vigne et du Vin Hors série, p 27-31.

Prior L. D., Cullis B. R., Sarooshi R. A. (1993) Influence of rootstock and trellis systems on the productivity of sultana grapevines. Australian Journal of Experimental Agriculture 33, 935-943.

Ravaz L. (1911) L'effeuillage de la vigne. Annales de l' Ecole Nationale d' Agriculture de Montpellier 11, 219-245.

Read P. E., Gu S. (2003) A century of American viticulture. Hortscience 38, 943-951.

Reynolds A. G., Wardle D. A. (2001) Rootstocks impact vine performance and fruit composition of grapes in British Columbia. HortTechnology 11, 419-427. 
Rives M. (1971) Statistical analysis of rootstock experiments as providing a definition of the terms vigour and affinity in grapes. Vitis 9, 280-290.

Robinson G. K. (1991) That BLUP is a good thing: The estimation of random effects. Statistical Science 6, 15-51.

Ruhl E. H., Clingeleffer P. R., Nicholas P. R., Cirami R. M., McCarthy M. G., Whiting J. R. (1988) Effect of rootstocks on berry weight and $\mathrm{pH}$, mineral-content and organic-acid concentration of grape juice of some wine varieties. Australian Journal of Experimental Agriculture 28, 119-125.

Sauer M. R. (1968) Effects of vine rootstocks on chloride concentration in Sultana scions. Vitis 7, 223-226.

Smart R. E. (1991) Sunlight into Wine. (Winetitles: Adelaide)

Soar C. J., Dry P. R., Loveys B. R. (2006) Scion photosynthesis and leaf gas exchange in Vitis vinifera L. cv. Shiraz: Mediation of rootstock effects via xylem sap ABA. Australian Journal of Grape and Wine Research 12, 82-96.

Stirling G. R., Cirami R. M. (1984) Resistance and tolerance of grape rootstocks to South Australian populations of root-knot nematode. Australian Journal of Agriculture and Animal Husbandry 24, 277-282.

Striegler R. K., Howell G. S., Flore J. A. (1993) Influence of rootstock on the response of seyval grapevines to flooding stress. American Journal of Enology and Viticulture 44, 313-319.

Sule S., Burr T. J. (1998) The effect of resistance of rootstocks to crown gall (Agrobacterium spp.) on the susceptibility of scions in grape vine cultivars. Plant Pathology 47, 84-88.

Verbyla A. P., Cullis B. R. (1992) The analysis of multistratum and spatially correlated repeated measures data. Biometrics 48, 1015-1032.

Walker M. A., Clingeleffer P. R., Kerridge G. H., Ruhl E. H., Nicholas P. R., Blackmore D. H. (1998) Effects of the rootstock Ramsey (Vitis champini) on ion and organic acid composition of grapes and wine, and on wine spectral characteristics. Australian Journal of Grape and Wine Research 4, 100-110.

Walker M. A., Wolpert J. A., Weber E. (1994) Viticultural characteristics of Vr hybrid rootstocks in a vineyard site infected with grapevine fanleaf virus. Vitis $\mathbf{3 3}, 19$ 23.

Walker R. R., Blackmore D. H., Clingeleffer P. R., Correll R. L. (2002) Rootstock effects on salt tolerance of irrigated field-grown grapevines (Vitis vinifera L. cv. Sultana). 1. Yield and vigour inter-relationships. Australian Journal of Grape and Wine Research 8, 3-14. 
Walker R. R., Blackmore D. H., Clingeleffer P. R., Correll R. L. (2004) Rootstock effects on salt tolerance of irrigated field-grown grapevines (Vitis vinifera L. cv. Sultana) 2. Ion concentrations in leaves and juice. Australian Journal of Grape and Wine Research 10, 90-99.

Walker R. R., Read P. E., Blackmore D. H. (2000) Rootstock and salinity effects on rates of berry maturation, ion accumulation and colour development in Shiraz grapes. Australian Journal of Grape and Wine Research 6, 227-239.

Wei X., Clingeleffer P. R., Sykes S. (2003a) Narrow-sense heritability estimates for yield and quality characteristics in CSIRO's table grape breeding program. Acta Horticultura 603, 173-179.

Wei X., Sykes S. R., Clingeleffer P. R. (2003b) Effects of selection on early stage genetic evaluation for berry weight in breeding table grapes. Plant Breeding 122, 7782 .

Wei X. M., Sykes S. R., Clingeleffer P. R. (2002) An investigation to estimate genetic parameters in CSIRO's table grape breeding program. 2. Quality characteristics. Euphytica 128, 343-351.

Welham S., Cullis B., Gogel B., Gilmour A., Thompson R. (2004) Prediction in linear mixed models. Australian \& New Zealand Journal of Statistics 46, 325-347.

Wheal M., Clingeleffer P. R., Sykes S. (2002) Grapevine rootstocks for Australian conditions. In "Plant Breeding for the 11th Millenium' Proceedings of the 12th Australasian Plant Breeding Conference 15-20th September'. Perth, Western Australia. (Ed. JA Coomb) pp. 161-166. (Australasian Plant Breeding Association Inc.)

Whiting J. R. (2004) Grapevine Rootstocks. In 'Viticulture'. (Eds PR Dry and BG Coombe) pp. 167-188. (Winetitles: Adelaide)

Whiting J. R., Orr K. (1990) 99 Richter and 101-14 rootstocks susceptible to waterlogging. The Australian Grapegrower and Winemaker 321, 60.

Williams L. E., Smith R. J. (1991) The effect of rootstock on the partitioning of dry weight, nitrogen and potassium, and root distribution of Cabernet Sauvignon grapevines. American Journal of Enology and Viticulture 42, 188-122.

Wolfinger R. D. (1996) Heterogeneous variance: covariance structures for repeated measures. Journal of Agricultural, Biological, and Environmental Statistics 1, 205230.

Zerihun A., Treeby M. T. (2002) Biomass distribution and nitrate assimilation in response to N supply for Vitis vinifera $\mathrm{L}$. cv. Cabernet Sauvignon on five Vitis rootstock genotypes. Australian Journal of Grape and Wine Research 8, 157-162. 
Table 1: Species pedigrees of hybrid rootstock genotypes examined within the field trial. Where possible, the species of the grandparents of the hybrid genotypes within the field trial are shown. In some cases, it was not possible to resolve the pedigree of a particular rootstock genotype: u.p.v.r $=$ unresolved pedigrees including $V$. Vinifera and $V$. rotundifolia; u.p. = completely unresolved pedigrees. $V$. can $\times V . r u p=$ natural $V$. candicans $\mathrm{x} V$. rupestris hybrid.

\begin{tabular}{|c|c|c|}
\hline \multirow[t]{2}{*}{ Hybrid Code } & \multicolumn{2}{|c|}{ Pedigree } \\
\hline & Parent 1 & Parent 2 \\
\hline $1-5$ & $V$. berlandieri $\mathrm{x} V$. berlandieri & $V$. berlandieri $\mathrm{x} V$. berlandieri \\
\hline 6 & $V$. berlandieri $\mathrm{x} V$. berlandieri & u.p. \\
\hline $7-13$ & $V$. cinerea $\times$ V cinerea & $V$. cinerea $\times V$. cinerea \\
\hline $14-15$ & $(V$. can $\times V \cdot$ rup $) \times V$. riparia & $V$. berlandieri $\mathrm{x} V$. rupestris \\
\hline $16-18$ & $(V$. can $\times V$. rup $) \times V$. riparia & $V$. berlandieri $\mathrm{x} V$. riparia \\
\hline $19-21$ & $(V$. can $\times V$. rup $) \times V$. riparia & $V$. berlandieri $\mathrm{x} V$. berlandieri \\
\hline $22-23$ & $(V$. can $\times V \cdot$ rup $) \times(V$. can $\times V \cdot r u p)$ & $V$. vinifera $\times V$. vinifera \\
\hline $24-28$ & u.p.v.r & u.p. \\
\hline $29-31$ & $V$. vinifera $\times$ V. rotundifolia & u.p. \\
\hline 32 & u.p.v.r & V. rotundifolia \\
\hline $33-55$ & $V$. longii $\mathrm{x} V$. longii & $V$. vinifera $\times V$. vinifera \\
\hline
\end{tabular}


Table 2: Genetic correlation coefficients $\left(r_{g}\right)$ for fruit yield between years obtained from the REML model indicate a gradual decline in the correlation between genotype performance over the six years of observations.

\begin{tabular}{cccccc}
\hline Year & 1994 & 1995 & 1996 & 1997 & 1998 \\
\hline 1993 & 0.83 & 0.80 & 0.76 & 0.74 & 0.69 \\
1994 &. & 0.87 & 0.90 & 0.83 & 0.80 \\
1995 &. &. & 0.86 & 0.87 & 0.86 \\
1996 &. &. &. & 0.91 & 0.92 \\
1997 &. &. &. &. & 0.93 \\
\hline
\end{tabular}


Table 3: Generalised broad-sense heritability estimates for pruning weight, yield and berry weight, calculated for each year of the study. Mean values for all years are presented.

\begin{tabular}{cccc}
\hline Year & Pruning Weight & Yield & Berry Weight \\
\hline 1993 & 0.90 & 0.81 & 0.63 \\
1994 & 0.90 & 0.88 & 0.75 \\
1995 & 0.90 & 0.86 & 0.78 \\
1996 & 0.89 & 0.91 & 0.73 \\
1997 & 0.90 & 0.88 & 0.50 \\
1998 & 0.87 & 0.89 & 0.76 \\
Mean & 0.89 & 0.87 & 0.69 \\
\hline
\end{tabular}


Table 4: The six genotypes ( $10 \%$ of those examined) that best fit a selection range designed to identify rootstock genotypes that confer intermediate vigour while maintaining suitable yield levels, berry size, and Ravaz Index (yield/pruning weight) are shown. Mean BLUP values over the six years of observations are provided for each trait.

\begin{tabular}{ccccc}
\hline Genotype & PrunWt $(\mathrm{kg})$ & Yield $(\mathrm{kg})$ & BeWt $(\mathrm{kg})$ & Ravaz Index \\
\hline 4 & 1.48 & 9.59 & 1.32 & 6.50 \\
5 & 1.24 & 8.60 & 1.31 & 6.92 \\
19 & 1.62 & 10.20 & 1.38 & 6.29 \\
40 & 1.18 & 8.11 & 1.36 & 6.87 \\
47 & 1.76 & 9.62 & 1.35 & 5.46 \\
2 Mer. 5489 & 1.85 & 9.25 & 1.30 & 5.01 \\
\hline
\end{tabular}


a)
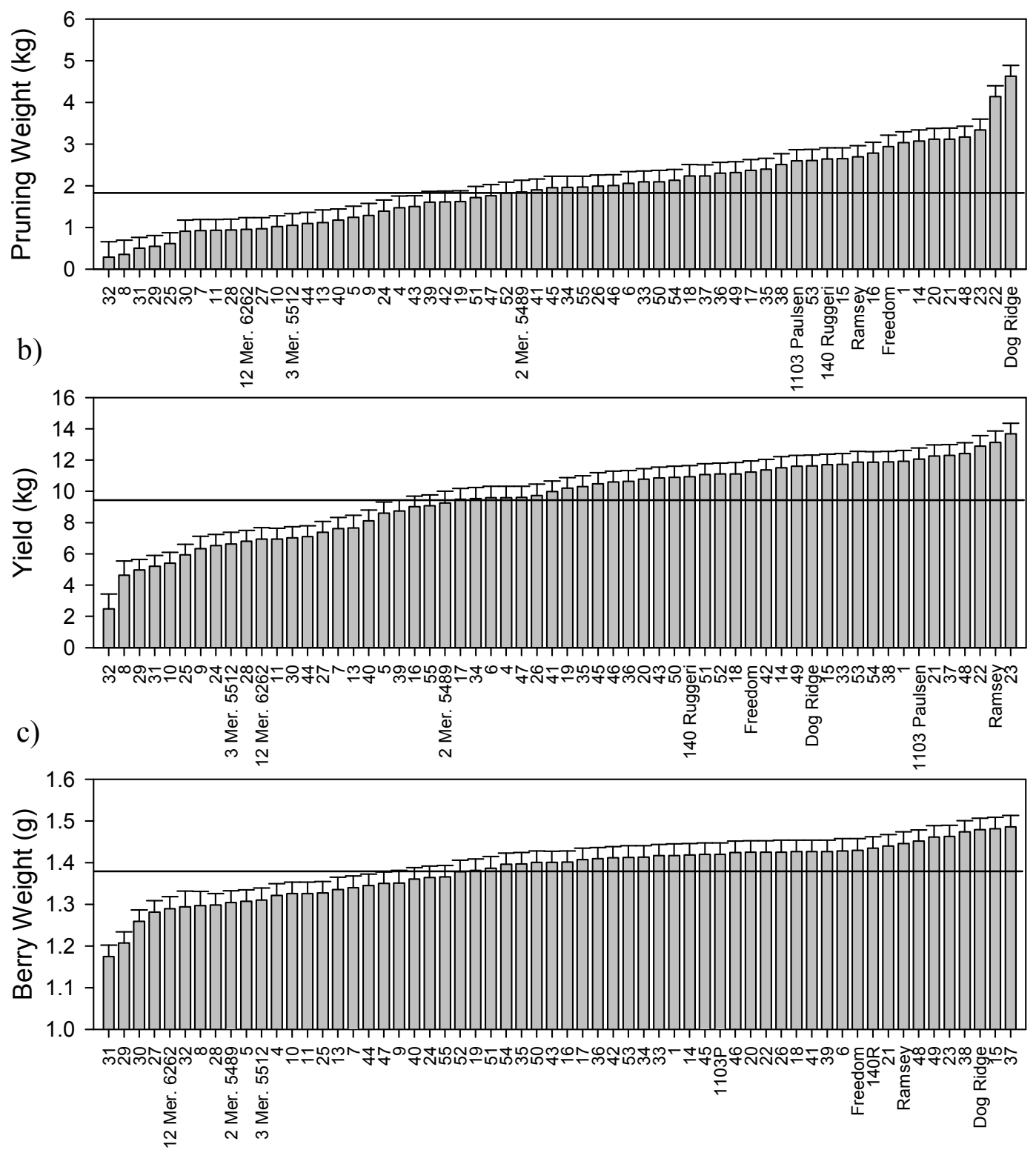

Genotype 
a)

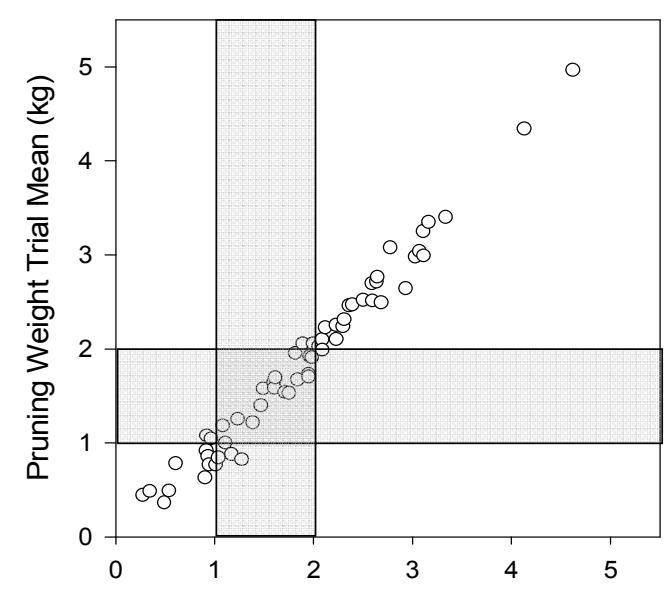

c)

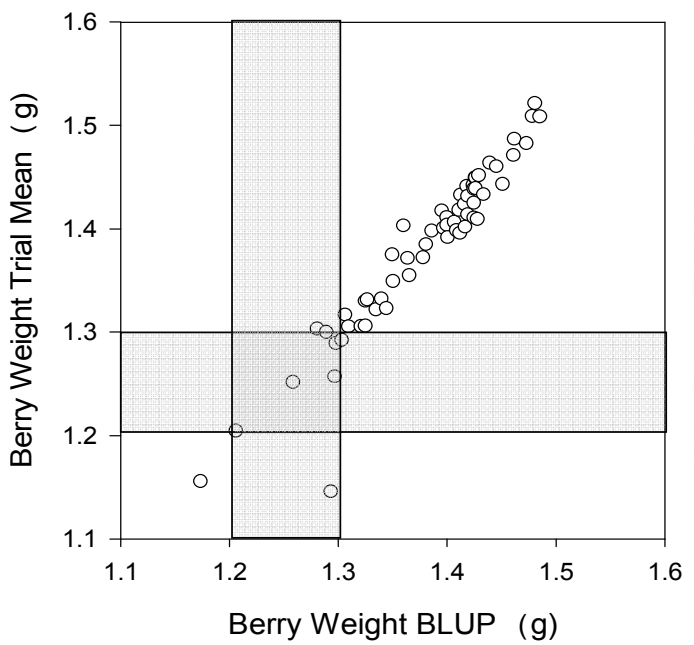

b)
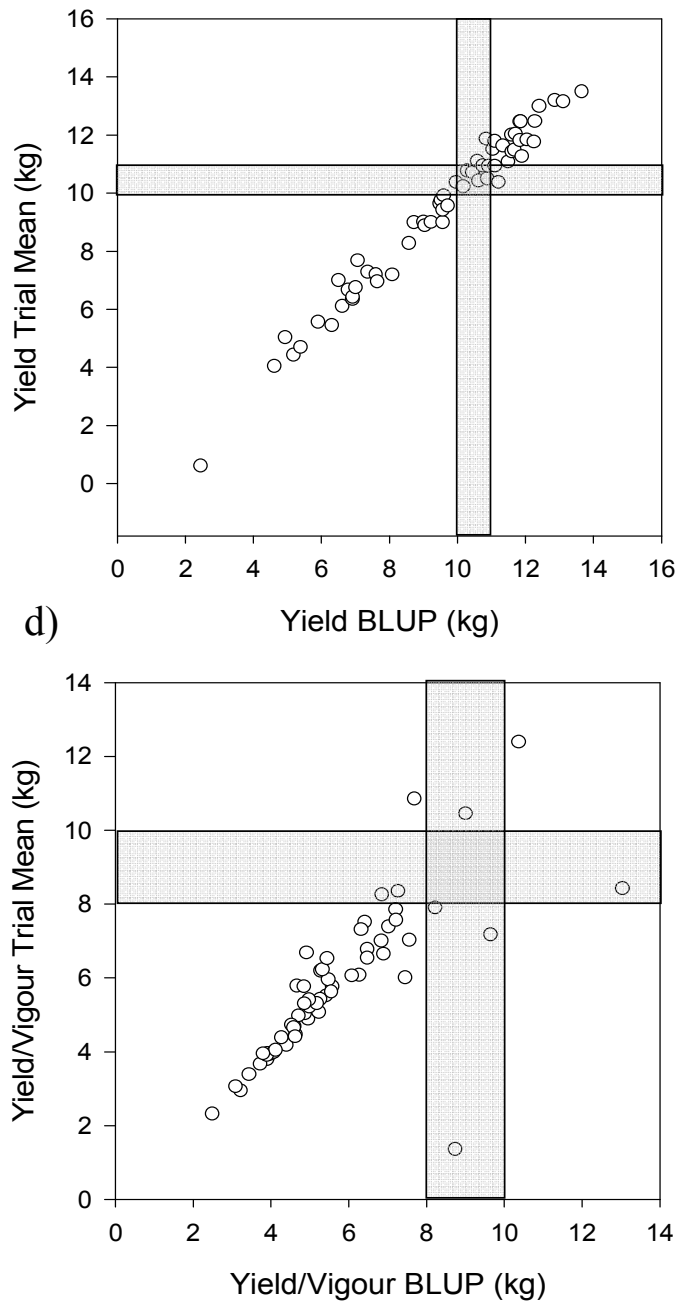


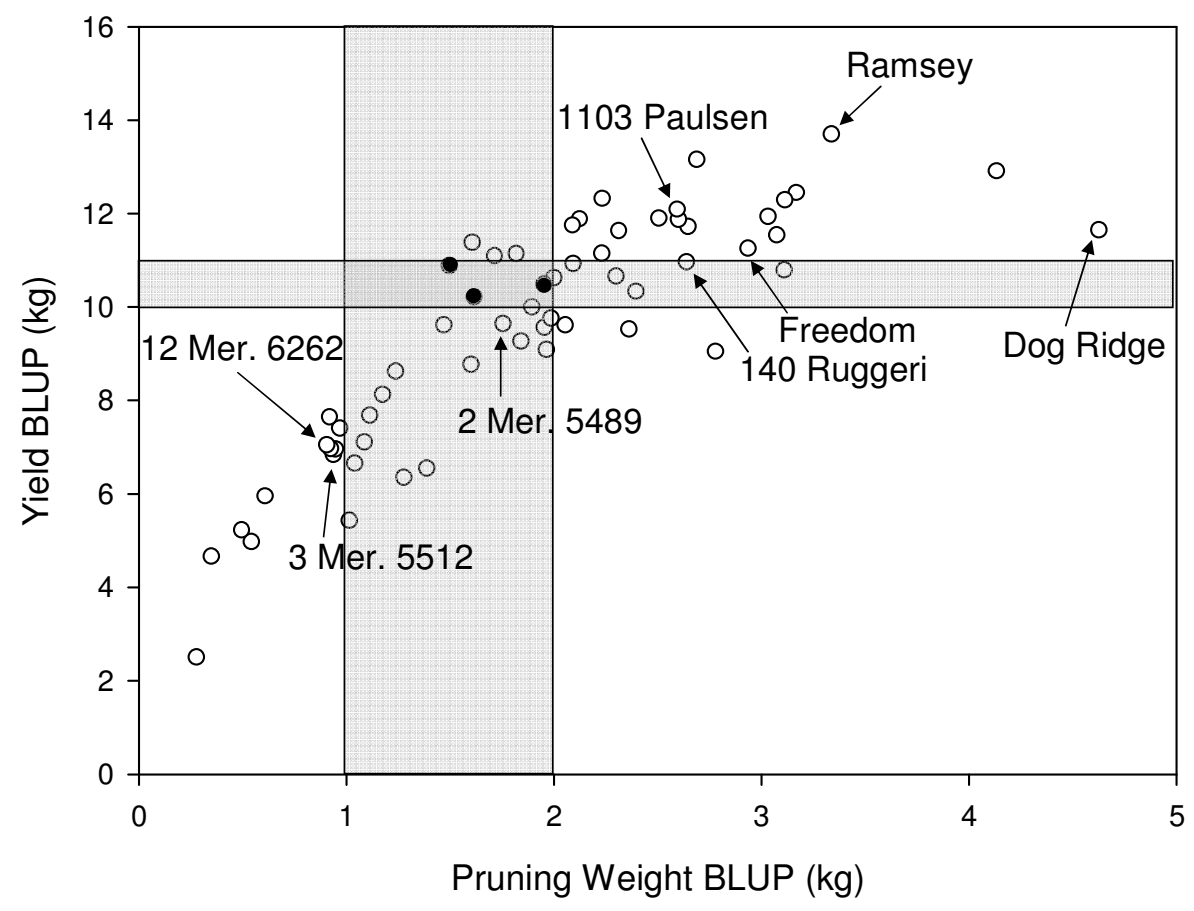




\section{Figure legends:}

Figure 1: The Best Linear Unbiased Predictors (provided with prediction standard errors) for the pruning weight (a), fruit yield (b) and berry weight (c) of Shiraz grapevines grafted to the 60 rootstock genotypes. The trial mean of the BLUP values for all rootstock genotypes is displayed with a horizontal bar for each trait. Genotypes 2, 3 and 12 are CSIRO selections and have been additionally labelled to allow ease of comparison with traditional varieties.

Figure 2: Comparisons of genotype performance calculated with Best Linear Unbiased Predictions (BLUPs) and trial arithmetic means for pruning weight (a), yield (b) and berry weight (c) indicate clear differences in the predicted performance of genotypes based on the two approaches. The ratio of yield to vigour calculated from genotype trial means is compared to that calculated from genotype BLUPs (d) showing a magnification in the discrepancies between predictions based on the two approaches. The shaded areas allow comparison of the genotypes that would be selected under an arbitrary selection range based on BLUP values versus arithmetic means.

Figure 3: Best Linear Unbiased Predictions (BLUPs) for yield are plotted against pruning weight. The performance of the traditional rootstock varieties and the three CSIRO rootstock selections included in the study are shown. When a selection range of between 10.0 and $11.0 \mathrm{~kg}$ for fruit yield and 1.0 and $2.0 \mathrm{~kg}$ for pruning weight is applied, three genotypes (filled black) that satisfy these criteria are identified. 